\title{
Astrolabios andalusíes e hispanos: de la precisión a la suntuosidad*
}

\author{
Azucena Hernández PÉREZ \\ Universidad Complutense de Madrid, \\ Departamento de Historia del Arte I (Medieval) \\ azucena.hernandezperez@gmail.com
}

\section{RESUMEN}

El astrolabio es un instrumento de precisión para uso astronómico que nació en Grecia en torno al s. I a.C. y, en manos del Islam, a partir del s. VIII se revistió de una dimensión suntuaria como instrumento al servicio de la religión y del poder civil. Un recorrido cronológico desde el $\mathrm{s}$. X al XV, de la mano de los astrolabios andalusíes y de los realizados en los reinos cristianos hispanos, evidencia la evolución de su dimensión decorativa. Los astrolabios que nos han llegado son de latón y los análisis metálicos realizados en las aleaciones usadas en cada una de sus partes nos ayudan a perfilar la configuración de los talleres astrolabistas. Los Tratados del Astrolabio conservados, en árabe, latín y castellano, nos permiten conocer el proceso teórico de diseño, las aplicaciones y el modo de funcionamiento de los astrolabios.

Palabras clave: Astrolabio, astrolabista, latón, astronomía medieval, medida del tiempo.

\section{Andalusi and Hispanic Astrolabes: From Precision to Sumptuousness}

\begin{abstract}
The astrolabe is a two-dimensional model of the universe. The origins of this astronomical instrument were in Greece around the $1^{\text {st }}$ century BC. From the $8^{\text {th }}$ century the Islamic world developed it further to make it an instrument at the service of religion and, by adding decorative elements, also attractive to the civil power. A chronological journey from the $10^{\text {th }}$ to the $15^{\text {th }}$ centuries accompanied by both, the Andalusí astrolabes and those executed in the Hispanic Christian kingdoms, evidences the evolution of their sumptuary dimension. Astrolabes that have attained our days are made of brass. The analysis of the alloy composition of each part of the astrolabe, helps to approach the layout of the medieval astrolabe workshops. The Astrolabe Treatises, written in Arabic, Latin and Castilian let us know the theoretical design process, the applications and operating mode of astrolabes.
\end{abstract}

Key words: Astrolabe, astrolabist, brass, medieval astronomy, timekeeping.

\footnotetext{
* Mi agradecimiento al Dr. Antonio Momplet por dirigir mi investigación sobre astrolabios medievales y a todos los profesores del Departamento de Historia del Arte I (Medieval) de la UCM por su inestimable ayuda, en especial al Dr. Herbert González, la Dra. Laura Fernández y la Dra. Susana Calvo. Gracias al Museo Arqueológico Nacional y en particular a la Dra. Ángela Franco y a Da Isabel Arias, por facilitarme el estudio a fondo del astrolabio taifa que allí se atesora.
} 
El éxito del astrolabio ${ }^{1}$ durante la Edad Media se debe fundamentalmente al modo en que conjuga la precisión y funcionalidad exigida a un instrumento científico con la suntuosidad que demandan los objetos vinculados al poder civil y religioso. La posibilidad que ofrece el astrolabio de determinar con exactitud la hora, así como de fijar la dirección de la Meca lo convirtió en instrumento esencial para el culto islámico en al-Andalus. Sus funciones de reloj lo introdujeron también en los monasterios cristianos españoles, para el establecimiento de las horas canónicas de rezo.

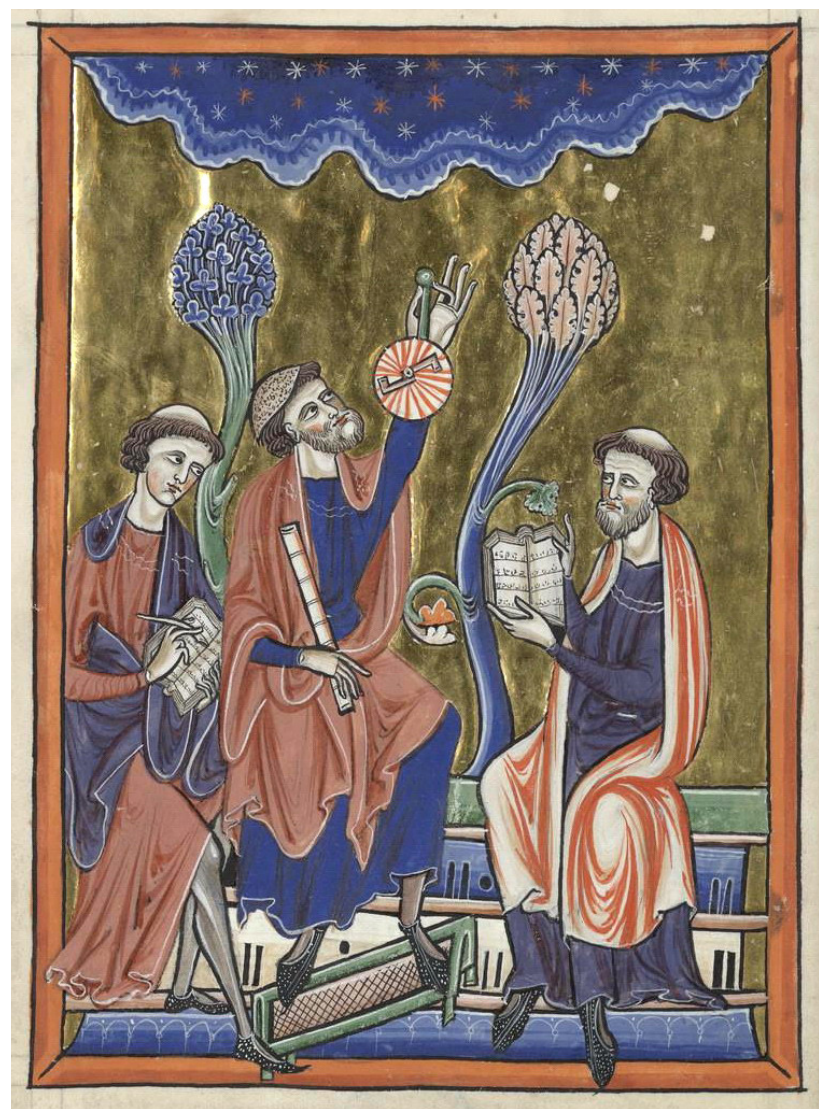

Fig. 1. Astrolabio en manos de monjes. Salterio de San Luis y Blanca de Castilla, primer cuarto del s. XIII. Bibliothèque de l'Arsenal de París, Ms. 1186, f. 1v.

El astrolabio experimentó, tanto en la cultura islámica como en la cristiana medieval, un proceso de legitimación doctrinal como imagen y símbolo del universo creado

1 El tipo de astrolabio al que se refiere este texto es el astrolabio planisférico, el más abundante y el mejor diseñado. Los otros dos tipos de astrolabios, el lineal y el esférico tuvieron poco éxito y solo nos han llegado descripciones de cómo eran y un ejemplar de astrolabio esférico realizado en 1480 por Mūsā que se conserva en el Museo de Historia de la Ciencia de Oxford. 
por Dios así como de la evidencia del paso del tiempo ${ }^{2}$. En el caso de al-Andalus destaca el texto contenido en las Memorias de 'Abd Allāh, último rey Zìrí de Granada donde el rey recoge las palabras de un sabio's: "En el Alcorán recito las palabras de Dios y en el astrolabio reflexiono sobre la creación de Dios porque la astronomía es una manera de adorarlo".

En la cultura cristiana, el astrolabio se incorporó a ilustraciones de libros religiosos como la Genealogía Bíblica realizada, entre 1031 y 1060, en la abadía de SaintGermain-des-Prés de París donde Abraham aparece sosteniendo un astrolabio en su mano $^{4}$ o al Salterio de San Luis y Blanca de Castilla conservado en la Biblioteca del Arsenal de París que se inicia con una ilustración a página completa en la que tres monjes utilizan un astrolabio mientras toman nota en unos libros ${ }^{5}$ (Fig. 1). Ya "bendecido" por la autoridad religiosa, el astrolabio salta a manos de reyes ${ }^{6}$ como objeto científico y suntuario revestido de significado simbólico.

\section{El astrolabio y sus orígenes}

Básicamente, el astrolabio es una representación bidimensional de la esfera celeste. Es un instrumento de precisión cuyo uso principal es astronómico pero cuya progresiva sofisticación le hizo servir para muchas otras funciones como la de medida del tiempo y la determinación de direcciones geográficas de modo que lo convirtieron en un objeto al servicio del culto, tanto islámico como cristiano, durante el periodo medieval.

El término "astrolabio" (al'asturlāb en árabe medieval) viene del griego $\dot{\alpha} \sigma \tau \rho o \lambda \dot{\alpha} b ı v$ (de $\dot{\alpha} \sigma \tau \rho o$, astro y de $\lambda \dot{\alpha} \mu \sigma o l o v \omega$, tomar, coger, encontrar) y lo introdujo el astrónomo alejandrino Claudio Ptolomeo (100-170 d.C.). El fundamento teórico del astrolabio es la proyección estereográfica ${ }^{7}$ de la esfera celeste sobre el plano del ecuador que fue formulada por Hiparco de Nicea en el s. II a.C. y recogida posteriormente por Ptolomeo tanto en su obra Planisphaerium ${ }^{8}$ (ca. 150 d.C.) como en su tra-

2 A. BORRELLI, Aspects of the Astrolabe. 'Architectonica ratio' in tenth and eleventh century Europe, Munich, 2008, pp. 210-213 y 220-221.

3 E. LÉVI-PROVENÇAL y E. GARCÍA GÓMEZ, El siglo XI en 1 $1^{a}$ persona: Las “Memorias” de 'Abd Allāh, último rey Zīrí de Granada, destronado por los almorávides (1090), Madrid, 1995, p. 317.

4 Bibliotèque nationale de France, Ms Lat. 12117, f. 106r.

5 Bibliotèque de l'Arsenal, Ms. 1186, f. 1v.

6 J.M. MILLÁS VALLICROSA, Las tablas astronómicas del rey D. Pedro el Ceremonioso, MadridBarcelona, 1962, p. 82. Está documentada la compra de un astrolabio por el rey Pedro IV de Aragón en junio de 1374. También está registrada la que hizo en 1380 su hijo el rey Juan I para regalar el astrolabio a su esposa Violante de Bar: J. MASSÓ I TORRENTS, "Inventari dels bens mobles del rey Martí d'Aragó", Revue Hispanique, XII, 42 (1905), pp. 492 y 500. El rey Martín I de Aragón tenía, en su biblioteca privada, situada junto a su dormitorio, un astrolabio y una bolsa de cuero con siete láminas de astrolabio.

7 La proyección de una esfera sobre un plano es el resultado de transportar cada uno de los puntos de la esfera a un plano desde un determinado punto de mira situado en una recta perpendicular a dicho plano. La proyección estereográfica, la más frecuente en los astrolabios, toma como plano de proyección el ecuador de la esfera celeste y como punto de mira el polo sur celeste.

8 A. BORRELLI, op. cit., p.19; M. VILADRICH I GRAU, "El astrolabio", Instrumentos astronómicos en la España medieval y su influencia en Europa, catálogo de la exposición, Santa Cruz de la Palma, 1985, p. 27. 
tado astronómico Almagesto 9 . El contenido del Planisphaerium de Ptolomeo formó parte de textos posteriores de autores como Zeón de Alejandría (375 d.C.) y Severus Sebokht, obispo de Kennesrin en Siria (640 d.C.). De todos estos textos se deriva el primer Tratado del Astrolabio del que tenemos conocimiento que escribió, en griego, Juan Philopon de Alejandría el año 642 d.C. Esta obra confirma que en el imperio bizantino se mantuvo la tradición astrolabista griega y, el hecho de que este primer Tratado del Astrolabio se escribiera justo al comienzo de la era islámica, lo convierte en el nexo de unión entre los orígenes griegos del astrolabio y su gran desarrollo en el mundo islámico ${ }^{10}$.

No nos ha llegado ningún astrolabio griego pero sí un sofisticado instrumento astronómico de bronce ${ }^{11}$, similar al astrolabio, realizado en Grecia en el periodo helenístico que permite suponer que hubo astrolabios en Grecia al menos desde el s. II d.C. ${ }^{12}$ y que estos instrumentos pudieron llegar a manos islámicas en el s. VIII, juntamente con los fundamentos teóricos ya referidos. No obstante lo anterior, la sofisticación del astrolabio, tal y como nos ha llegado, es islámica, está ligada al extraordinario desarrollo de la astronomía y las matemáticas en esa cultura, y la fiabilidad y precisión de sus medidas son debidas al virtuosismo islámico en la técnica del grabado sobre metal, a su minuciosidad y su culto al detalle.

Todos los astrolabios son de forma circular con un sistema de suspensión en su parte superior. Su diámetro oscila entre $\operatorname{los} 10$ y los $30 \mathrm{~cm}$ (excluido el sistema de suspensión) y su peso entre $0.5 \mathrm{~kg}$ y $2 \mathrm{~kg}$. Un astrolabio consta de varios elementos entre los que destaca la araña que, situada en la faz del astrolabio, es la parte donde se concentran los elementos decorativos, tanto en los astrolabios andalusíes como en los hispanos medievales. El dorso del astrolabio es la parte que mejor lo identifica. En él se encuentra la inscripción de autoría y fecha (si la hay) y, la presencia del llamado calendario zodiacal que es una de las características identificativas de los astrolabios andalusíes y los latinos de influencia andalusí y es otro de los elementos que evidencian la sociedad culturalmente dual, islámico-cristiana de la España medieval ${ }^{13}$.

9 C. MÍNGUEZ, "El prefacio al Almagesto de Ptolomeo", La filosofía de los científicos, Sevilla, 1995, p. 17. Ptolomeo tituló su magna obra astronómica Sintaxis Matemática, pues la astronomía es una parte de la matemática. En la primera traducción de esta obra al árabe, realizada en Bagdad en el s. IX por el lingüista y científico Husain ibn Ishaq (809-873 d.C.) bajo el patrocinio del califa abasí al-Ma'mūn, se le cambió el título por Al-Magistí ("El más Grande”). Las posteriores traducciones al latín la identificaron ya como Almagestum, que es como se la conoce hoy.

10 R.T. GUNTHER, The Astrolabes of the World, vol. I. Eastern Astrolabes, Londres, 1976, p. 59.

11 Se trata del conocido como Mecanismo de Antikythera sobre el que hay abundante bibliografía. Ver T. FREETH et al, "Decoding the Antikythera Mechanism: Investigation of an ancient astronomical calculator", Nature, 444, 7119 (2006), pp. 587-591.

12 O. NEUGEBAUER, "The early history of the Astrolabe", Isis, 40 (1949) p. 242.

13 J. SAMSÓ, Las ciencias de los Antiguos en al-Andalus, Almería, 2011, p. 33. El calendario zodiacal consta de dos círculos excéntricos, el más exterior con los doce signos del Zodiaco y el más interior con los doce meses del calendario juliano. El calendario zodiacal establece una correspondencia biunívoca entre cada fecha del año juliano y la longitud del sol. Esta es una de las consecuencias de la influencia de la tradición astronómica latino-isidoriana en la ciencia andalusí. D.A. KING, op. cit., 1983, p. 533. Está documentada una escuela de astronomía y astrolábica en otra sociedad "dual" como fue el Egipto copto en la que destaca la figura de al-Asad Ibn al-Assāl. La presencia de los dos calendarios en el dorso de los astrolabios islámicos solo se da de forma generalizada en al-Andalus y esporádicamente en el Egipto copto. Solo nos ha llegado un 
Las láminas, situadas bajo la araña, en número que oscila entre uno y nueve, están grabadas por ambas caras y cada una sirve para ser utilizada en una determinada latitud, incluyendo una inscripción en su centro con la latitud y la lista de ciudades en que se puede usar. Las láminas llevan grabadas las curvas almicantarates y acimutales que conforman el sistema de coordenadas que permite ubicar los astros en la esfera celeste respecto del horizonte del observador ${ }^{14}$. Son también las láminas las que llevan grabadas las curvas horarias que permiten el uso del astrolabio como reloj. Adicionalmente, los astrolabios andalusíes añaden, intercaladas, las marcas de las cinco horas de rezo que marca el Corán.

Los astrolabios realizados en territorio islámico están firmados y fechados pues la profesión de asturlabi (astrolabista) estaba muy valorada y el autor se hacía responsable de la precisión del instrumento y de su uso correcto. El astrolabista no era considerado un artesano del metal sino un científico, un astrónomo que, al igual que escribía textos, elaboraba los instrumentos que necesitaba para su trabajo ${ }^{15}$. En un periodo como la Edad Media en el que los artífices de objetos materiales solo firmaban sus obras en casos excepcionales, resulta interesante para el investigador trabajar con estos objetos cuidadosamente identificados. La situación cambia radicalmente cuando nos enfrentamos a los astrolabios elaborados en la Edad Media en la España cristiana en los que la firma y la fecha desaparecen inmediatamente y se debe recurrir a la datación en base a aspectos formales o a información astronómica grabada en el propio astrolabio.

\section{Evolución del astrolabio: de instrumento de precisión a objeto suntuario}

El astrolabio más antiguo que ha llegado a nuestros días no está fechado ni consta el lugar en el que se realizó. Por sus características se considera griego-helenístico de fecha indeterminada y retallado con grafía árabe en Bagdad a finales del s. VIII ${ }^{16}$. La

astrolabio con calendario copto en el dorso realizado en el Cairo por Hasan ibn Umar al-Naqqāsh en $681 \mathrm{H}$ (1282-1283 d.C.) y conservado en el Museo Türk ve Islâm Eserleri de Estambul D.A. KING, op. cit., 1999, p. 76. Hay certeza de que en el s. XIII se usaban en Egipto los calendarios copto e islámico lo cual justifica que se incorpore el calendario copto a los astrolabios D.A. KING, op. cit., 2005, p. 897, fig. 18a; J.M. MILLÁS VALLICROSA, Estudios sobre historia de la ciencia española, Madrid, 1987, p. 118. El uso del calendario juliano, que es solar y no lunar como lo es el islámico, se generalizó en las actividades agrícolas en el territorio de al-Andalus.

14 Almicantarates o curvas almicantarates (también llamadas almucantarates o almucantarats) son circunferencias de igual altura en la esfera celeste, paralelas a la circunferencia del horizonte del observador. En otras palabras, son a la esfera celeste lo que los paralelos son a la esfera terrestre pero dependientes de la latitud del observador. Dos objetos celestes situados a la misma altura sobre el horizonte para un cierto observador, estarán en el mismo almicantarate para la latitud de ese observador. Las curvas acimutales son a la esfera celeste lo que los meridianos son a la terrestre.

15 F.R. MADDISON, "Early astronomical and mathematical instruments", HS (History of Science), 2 (1963), p. 24.

16 D.A. KING, op. cit., 2005, pp. 403-437. Este astrolabio se considera ahora el "eslabón perdido" entre los astrolabios griegos y los islámicos. Lamentablemente fue uno de los objetos robados en el saqueo del Museo Arqueológico de Bagdad en abril de 2003 durante la Segunda Guerra del Golfo y se encuentra hoy en paradero desconocido. La sencillez de su diseño y su dorso carente de calendarios u otro tipo de información, 
evolución desde ese astrolabio griego, austero, preciso y solo dedicado a un uso astronómico al astrolabio islámico que, incrementando incluso su precisión, multiplica sus funciones añadiendo una dimensión decorativa y suntuaria, debe estudiarse desagregando las distintas partes que conforman el instrumento pues cada una de ellas aporta aspectos relevantes a esa evolución. De todas las innovaciones incorporadas al astrolabio, solo señalamos aquellas que lo convirtieron en un objeto suntuario de uso civil y religioso.

Las láminas de los astrolabios andalusíes incorporan, a sus elementos obligatorios, las marcas de las cinco horas del salat ó rezo islámico ${ }^{17}$. Como es lógico estas líneas de oración no están presentes en las láminas de los astrolabios latinos. Es importante resaltar que la calidad en el grabado de las láminas es un elemento diferenciador entre los astrolabios andalusíes y los realizados en los reinos cristianos hispanos que presentan, en algunos casos, errores en la grabación de las curvas y ausencias de algunas de ellas como es el caso del astrolabio de Zaragoza conservado en el Museo de Historia de la Ciencia de Oxford y que se fecha en torno a 1260. No quiere ello decir que no haya astrolabios latinos de gran calidad técnica como el de la colección del Aga Khan que se trata más adelante.

Ya se ha indicado anteriormente que la araña es el elemento del astrolabio que acoge toda su dimensión decorativa y suntuaria en el caso de los astrolabios hispanos medievales. Los astrolabios de otras partes del mundo presentan decoración, no solo en la araña, sino también en el dorso y en el trono (pieza de sustentación en la parte superior). Los tronos de algunos astrolabios andalusíes e hispanos también ofrecen algún aspecto decorativo pero en menor medida, siempre resaltando más la decoración de la araña.

Los tres astrolabios andalusíes del periodo omeya que nos han llegado incorporan el calendario zodiacal en el dorso y las marcas de las horas de rezo en las láminas, pero sus arañas son austeras como las griegas, con punteros estelares de forma geométrica (triángulo soportado en un trapecio), y sin ningún elemento decorativo. Como muestra, el astrolabio de Muhammad ibn al-Saffār realizado en Córdoba el 417 H (1026-1027 d.C.) y conservado en el Royal Scottish Museum de Edimburgo ${ }^{18}$.

En el periodo taifa se incorporan ya elementos decorativos en la mitad inferior de la araña. Los punteros estelares se estilizan, transformando los triángulos en puntas

corroboran el origen griego del instrumento y lo sitúan en el momento en que se produjo la transmisión transcultural, tanto de conocimientos astronómicos como de instrumentación de precisión, entre el mundo griego y el Islam.

17 Las cinco horas del salat o rezo islámico recogidas en el Corán son: maghrib (a la puesta del sol), $i s h a \bar{a}$ (al caer la noche, es decir al fin del crepúsculo vespertino), faŷr (al romper el día, es decir al inicio del crepúsculo matutino), zuhr (desde el mediodía, cuando no hay sombra, hasta el momento en que la sombra de un vástago vertical sobre el suelo es, como máximo, su longitud) y asr (a media tarde, cuando la sombra de un vástago vertical sobre el suelo duplica su longitud). La dificultad para determinar con exactitud los momentos exactos para realizar estas cinco oraciones puso en valor el astrolabio en los círculos religiosos.

18 Detalles sobre este astrolabio en: F. MADDISHON y A. TURNER, Science and technology in Islam, catálogo de la exposición, Londres, 1976, pp. 104-106; "Ficha catalográfica online del Astrolabio de Muhammad ibn al-Saffār. No de catálogo T.1959.62”, Catálogo del Royal Scottish Museum de Edimburgo. Edimburgo, 2013. http://www.nms.ac.uk/collections/details.php?item_id=216943\&terms=astrolabe\&key=description\&offset $=0 \&$ pos $=3 \&$ tot $=5$ (última consulta 30/1/2014). 
finas y curvadas y los trapecios en formas lobuladas y perforadas de mayor elegancia. Los punteros pierden robustez y son más susceptibles de sufrir deformaciones o roturas que perjudiquen el uso del astrolabio, pero la dimensión decorativa se convierte en esencial y ya no habrá vuelta atrás. Sin duda, la más hermosa araña taifa que nos ha llegado es la del astrolabio fechado en 460 H (1067-1068 d.C. $)^{19}$ (Fig. 2) y conservado en el Museo de Historia de la Ciencia de Oxford, obra de uno de los grandes astrolabistas andalusíes, Ibrāhīm ibn Sa'īd al-Shalī, activo primero en Toledo y luego en Valencia, tras la conquista cristiana de Toledo. Ibrāhīm ibn Sa'īd al-Shalī introduce en sus arañas elementos decorativos de tipo arquitectónico y otros zoomórficos además de incrementar la estilización y dinamización visual de los punteros estelares. Suyo es también el astrolabio que conserva el Museo Arqueológico Nacional de Madrid.

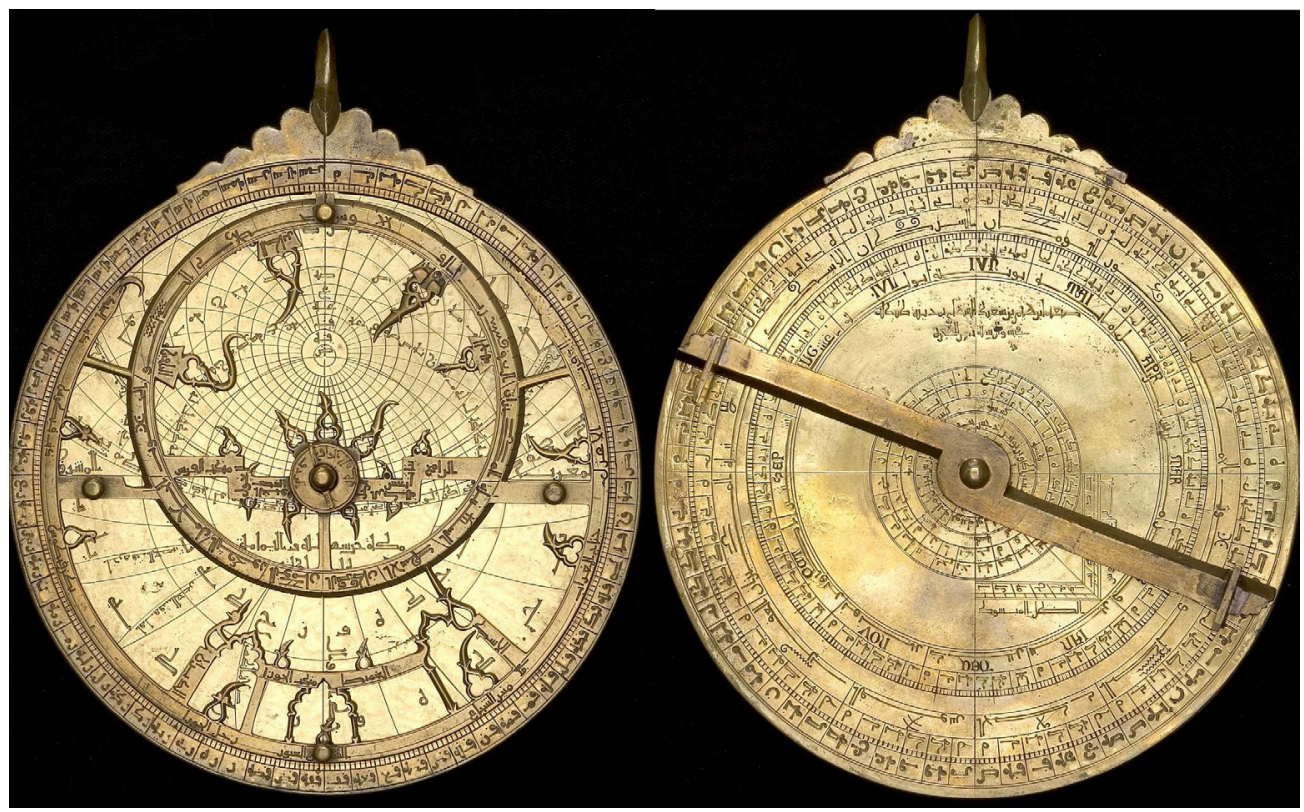

Fig. 2. Astrolabio taifa de Ibrāhīm ibn Sa'̄̄d al-Shalī, Toledo, 460 H (1067-1068 d.C.). Museo de Historia de la Ciencia de Oxford ( $\mathrm{n}^{\mathrm{o}}$ inv. 55331).

No nos ha llegado ningún astrolabio almorávide quizá porque se construyeron pocos para uso civil y religioso al ser mirados con recelo por los fundamentalistas islá-

19 Detalles de este astrolabio en: R.T. GUNTHER, op. cit., pp. 253-256; J.VERNET y J. SAMSÓ, Instrumentos astronómicos en la España medieval y su influencia en Europa, Santa Cruz de la Palma, 1985, pp. 82-83; El legado científico andalusí, Madrid, 1992, p. 223; y "Ficha de Inventario n 55331", Catálogo online de los Astrolabios del Museo de Historia de la Ciencia de Oxford, Oxford, 2013. http://www.mhs.ox.ac. uk/astrolabe/catalogue/browseReport/Astrolabe_ID=154.html (última consulta 30/1/2014). 
micos, quienes los consideraban objetos de origen pagano, cosa cierta pues nacieron en Grecia.

En el periodo almohade resurge la astrolábica andalusí con una figura muy relevante, el sevillano Muhammad ibn Fattūh al-Jamā'irī. Sus astrolabios tienen arañas similares, identificativas de este astrolabista, con un círculo inscrito en la parte inferior central, entre la banda ecuatorial y el círculo de Capricornio así como dos elementos rectangulares, a modo de torres, en los extremos de la banda ecuatorial. Varias de estas arañas conservan las incrustaciones en plata de unos punteros estelares que se han convertido ya en elementos filiformes y serpenteantes para señalar correctamente la posición de la estrella. A modo de ejemplo de este conjunto de astrolabios sevillanos destaca el que realizó al-Jamā'irī en Sevilla en 621 H (1224-1225 d.C.) ${ }^{20}$ (Fig. 3), conservado en el Museo de Historia de la Ciencia de Oxford.

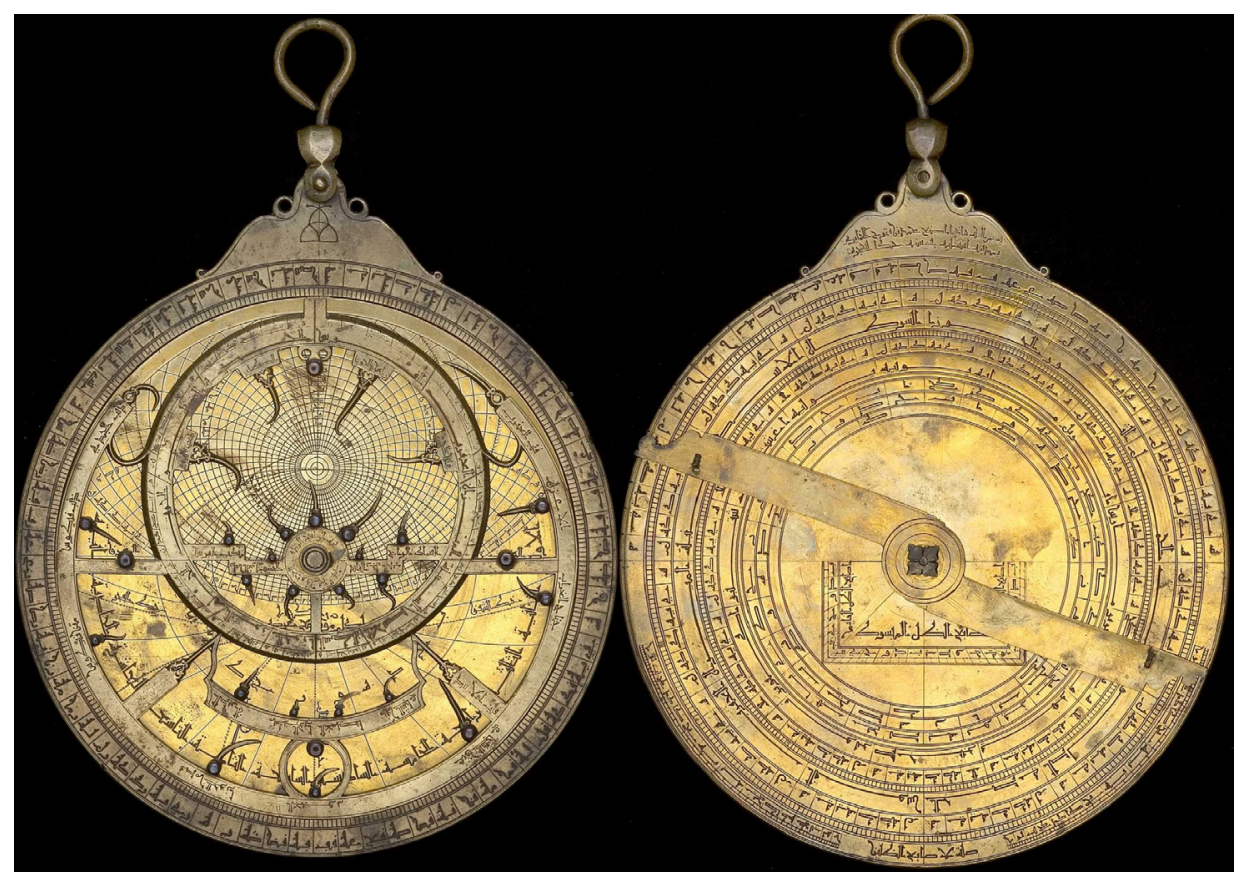

Fig. 3. Astrolabio almohade de Muhammad ibn Fattūh al-Jamā’irī, Sevilla, 621 H (12241225 d.C.). Museo de Historia de la Ciencia de Oxford ( $\mathrm{n}^{\circ}$ inv. 50934).

Se cierra este recorrido por los periodos históricos de al-Andalus con los astrolabios nazaríes. Alguno de ellos ofrece la novedad de contar con punteros estelares en forma de palmeta digitada esquemática. De este tipo es el astrolabio de Ahmad ibn

20 Detalles de este astrolabio en: R.T. GUNTHER, op. cit., pp. 276-277; "Ficha de Inventario n' 50934", Catálogo online de los Astrolabios del Museo de Historia de la Ciencia de Oxford, Oxford, 2013. http://www. mhs.ox.ac.uk/astrolabe/catalogue/browseReport/Astrolabe_ID=153.html (última consulta 30/1/2014). 
Husayn ibn Bāso firmado en Granada en 664 H (1265-1266 d.C. $)^{21}$ y conservado en la Real Academia de la Historia de Madrid. Este astrolabista es otra figura relevante de la astronomía andalusí y está documentada su actividad como amin awqat alsalawat, es decir, como responsable del establecimiento de las horas de rezo de la mezquita aljama de Granada ${ }^{22}$.

Tras este panorama general de los astrolabios andalusíes, nos adentramos en el campo más complejo y heterogéneo de los astrolabios realizados en los reinos cristianos hispanos durante la Edad Media. El primer problema es que no están firmados ni fechado ${ }^{23}$ y por tanto su adscripción a un periodo de tiempo o a una región geográfica es siempre hipotético y se basa, en unos casos, en las latitudes y ciudades inscritas en sus láminas, en ciertos datos astronómicos que permiten acotar periodos de tiempo y en el análisis formal. Con todas las inexactitudes que estos métodos conllevan, podemos hacer un recorrido a lo largo de los siglos X al XV para observar cómo se trasladan a los reinos cristianos hispanos las innovaciones técnicas y los elementos decorativos de los astrolabios andalusíes.

El astrolabio latino hispano más antiguo que nos ha llegado es incluso anterior en fecha, si su análisis de datación es correcto, al más antiguo andalusí conservado, es el conocido como astrolabio Destombes (por haber pertenecido al coleccionista francés Marcel Destombes), posiblemente realizado en Barcelona entre los años 966 y $1000^{24}$ frente el más antiguo andalusí que nos ha llegado fechado en 1026. La araña del astrolabio Destombes está incompleta porque no contiene los nombres de las estrellas de los punteros estelares y de hecho las posiciones de los punteros son incorrectas y no se corresponden con las coordenadas exactas de las estrellas incluidas en otros astrolabios. Parece como si, quien hiciera ese instrumento estuviera copiando un as-

21 Detalles de este astrolabio en: J. EIROA RODRÍGUEZ, Antigüedades Medievales. Catálogo del Gabinete de Antigüedades de la Real Academia de la Historia, Madrid, 2006, pp. 69-70; S. GARCÍA FRANCO, "Los astrolabios de la Real Academia de la Historia", Boletín de la Real Academia de la Historia, 136 (1955), pp. 298-308; R.T. GUNTHER, op. cit., pp. 279; E. SAAVEDRA Y MORAGAS, “Astrolabios árabes", Museo Español de Antigüedades, VI (1875), pp. 407-408; El legado científico andalusí, op. cit., 1992, p. 225; y Tesoros de la Real Academia de la Historia, Madrid, 2001, p. 249.

22 E. CALVO LABARTA, "Ibn Bāso's astrolabe in the Maghrib and East", From Baghdad to Barcelona. Studies in the Islamic Exact Sciences in Honour of Prof. Juan Vernet, vol. II, Barcelona, 1996, p. 755. Ibn Baso tuvo los cargos de amin awqat al-salawat (guardián de las horas de oración) e imam al-mu'adhdhinin (jefe de los muecines) de la mezquita Jami' de Granada.

23 Hasta el momento, el único astrolabio hispano firmado, del que tenemos información, es el que se conserva en el Museo de Bellas Artes de Boston. En él figura el nombre de Petrus Raimundi de Barcelona y el año 1375 .

24 A.M. MUNDÓ, “Analyse Paléographique de l'astrolabe 'Caroligien””, Physis, 32 (1995), pp. 303321. Este interesante estudio paleográfico de todas las inscripciones del astrolabio Destombes es el que ha permitido fijar la horquilla cronológica. 
trolabio andalusí sin entender muy bien lo que tenía entre manos ${ }^{25}$. Este interesante y controvertido astrolabio se conserva en el Instituto del Mundo Árabe de París ${ }^{26}$.

Los siglos XI y XII registran poca actividad astrolabista en los reinos cristianos. Sin embargo, a mediados del s. XIII se debió activar dicha producción con ejemplares notables que se datan durante el reinado de Alfonso X de Castilla. En Aragón la astrolábica vive su máximo esplendor en el s. XIV con el mecenazgo de los reyes Pedro IV el Ceremonioso y sus hijos Juan I el Cazador y Martín I el Humano.

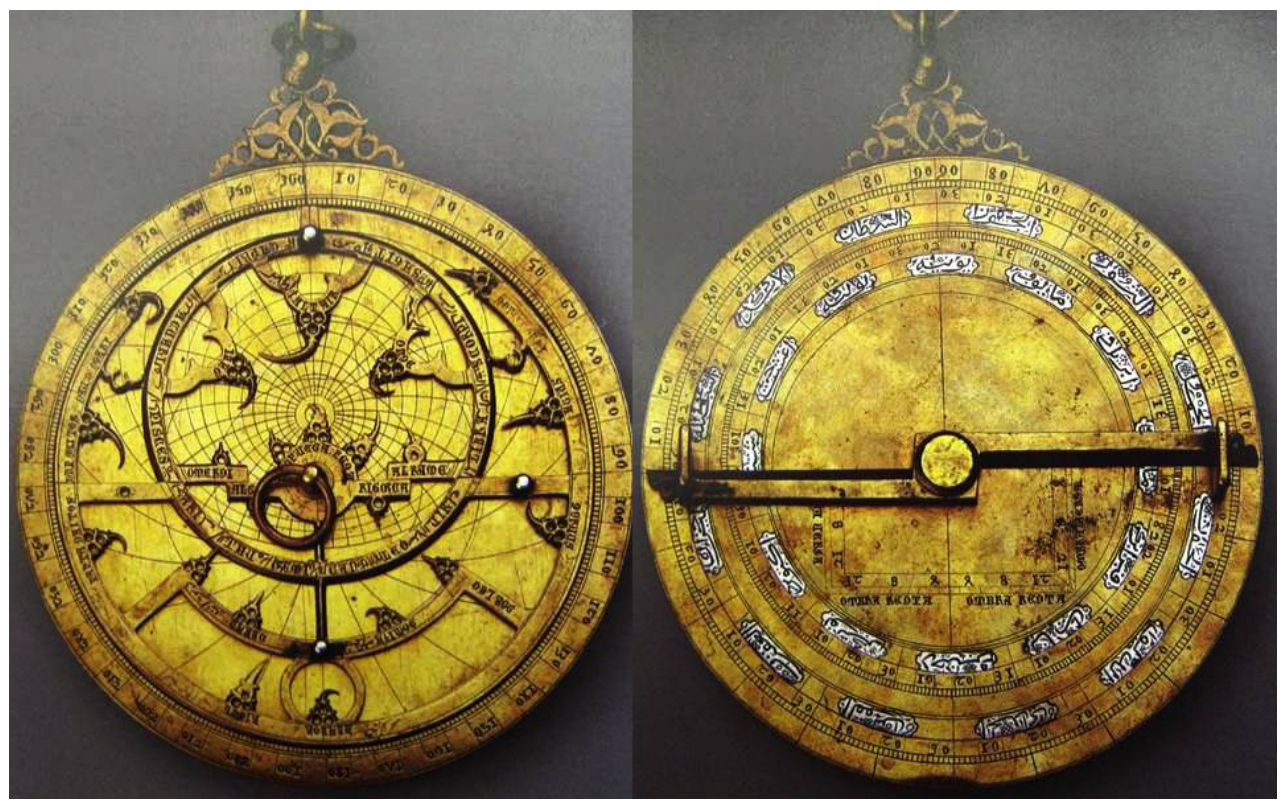

Fig. 4. Astrolabio latino posiblemente realizado en Toledo, $c a$. 1250-1500. Colección privada del Aga Khan ( $n^{\circ}$ inv. AKM 00611).

Del s. XIII destaca la araña del astrolabio hispano de la colección del Aga Khan, que se considera construido en Toledo entre 1250 y 1300 y que presenta semi-tretalóbulos como soporte de tres de sus punteros estelares, mostrando todos ellos una

25 Es mucho lo publicado sobre este astrolabio por las dudas sobre su autenticidad que emergieron cuando salió a la luz en 1962 proveniente de una colección particular. Destacan entre otros los estudios contenidos en: M. DESTOMBES, "Un astrolabe Carolingien et l'origine de nos chiffres arabes", Archives internationales d'histoire des sciences, 58-59 (1962), pp. 1-45; D. JACQUART, "Astrolabe caroligien dit Destombes", Les Andalousies de Damas à Cordoue, catálogo de la exposición, París, 2000, p. 242; D.A. KING, "The earliest known European astrolabe in the light of other early astrolabes", Physis, 32 (1995), pp. 359-404; R. D'HOLLANDER, "Étude comparative entre l'astrolabe dit Carolingien et l'astrolabe d'Abu Bakkr ibn Yusuf de Toulouse", Physis, 32 (1995), pp. 407-410; y J. SAMSÓ MOYA, "Roma et Francia (Ifranja) in Destombes carolingian astrolabe", Physis, 32 (1995), pp. 239-251.

26 Contamos con tres copias facsímil del astrolabio Destombes en España, una en el Museo de Ciencia y Tecnología de Madrid, otra en la Real Academia de Ciencias y Artes de Barcelona y la tercera en el Museo de la Ciencia de Tarrasa. 
elegante factura ${ }^{27}$ (Fig. 4). Adicionalmente, su dorso nos ofrece una interesante particularidad en forma de incrustaciones de plata nielada con inscripciones en árabe de los nombres de los signos del zodiaco y de los meses del calendario juliano, muestra de nuevo de la convivencia de culturas en el Toledo cristiano de la segunda mitad del s. XIII.

En los siglos XIV y XV se establecen ya en toda la Europa cristiana talleres astrolabistas que van desvinculando las formas decorativas de la tradición islámica e inciden en la dimensión suntuaria multiplicando los elementos ornamentales principalmente añadiendo formas tetralobuladas. Los reinos hispanos cristianos añaden una dimensión más a esta producción astrolabista derivada de la multiculturalidad cristiano-islámico-hebraica y es la inclusión de inscripciones en más de una de esas tres lenguas. Como ejemplo, el hermoso astrolabio hebreo posiblemente realizado en Toledo a finales del s. XIV y que se conserva en el Museo Británico ${ }^{28}$.

Tras este breve repaso por la producción astrolabista andalusí e hispana medieval se puede concluir que las formas decorativas se instalaron en los astrolabios desde el s. XI confirmando, como recogen las fuentes de la época, que esos instrumentos no estaban reservados a la reducida comunidad científica, exigente en términos de precisión pero no de estética, sino que formaban parte de los ajuares reales, nobiliarios y eclesiásticos tanto en los reinos cristianos como en los de al-Andalus.

\section{El astrolabio en su materialidad: estudios metálicos del latón}

Las dificultades para catalogar y datar los astrolabios que no están firmados, es decir todos los latinos, han llevado a utilizar los métodos técnicos de análisis del material que los componen, con el fin de determinar su posible origen y horquilla cronológica.

Todos los astrolabios medievales que nos han llegado son de latón ${ }^{29}$, aleación de cobre y zinc con una característica fundamental que la hace atractiva para su uso en la fabricación de objetos decorativos: tiene un aspecto y brillo similar al del oro con un bajo precio. El latón se usó desde el s. VI a.C. y se valoró por su maleabilidad y ductilidad que permite laminarlo muy fácilmente. Tiene un bajo coeficiente de dilatación,

27 Detalles de este astrolabio en D.A. KING "An astrolabe from medieval Spain with inscriptions in Hebrew, Arabic and Latin", In Synchrony with the Heavens. Studies in Astronomical Timekeeping and Instrumentation in Medieval Islamic Civilization. Vol 2: Instruments of Mass Calculation, Leiden-Boston, 2005, pp. 831-914; F. VALDÉS, “Al-Andalus: Oriente en Occidente”, Los mundos del Islam en la colección del Museo Aga Khan, catálogo de la exposición, Barcelona, 2009, p. 92; D.A. KING “An astrolabe from 14thcentury Christian Spain with inscriptions in Latin, Hebrew and Arabic. A Unique testimonial to an intercultural encounter", Suhayl, 3 (2002-2003), pp. 9-156; y S. MAKARIOU, Chefs-d'œuvre islamiques de l'Aga Khan Museum, París, 2007, pp. 28-29.

28 Detalles de este astrolabio en: B.R. GOLDSTEIN, "The Hebrew Astrolabe in the Adler Planetarium", Journal of Near Eastern Studies, 35 (1976), pp. 251-260; R.T. GUNTHER, op. cit., p. 304.

29 Para un conocimiento de las técnicas metalúrgicas de elaboración del latón en la Edad Media, tanto en el mundo islámico como en la Europa cristiana ver J. DAY, "Brass and Zinc in Europe from the Middle Ages until the Mid-Nineteenth Century", 2000 Years of Zinc and Brass, Londres, 1998, pp. 133-158; y P.T. CRADDOCK, S.C. LA NIECE, y D. HOOK, "Brass in the Medieval Islamic World", 2000 Years of Zinc and Brass, op. cit., 1998, pp. 73-114. 
lo cual permite mantener la exactitud de las medidas del astrolabio en condiciones térmicas distintas y permite ser grabado con facilidad, algo necesario para asegurar la precisión de las líneas y escalas graduadas que lleva. Las técnicas de trabajo sobre metal que se usan en la fabricación de los astrolabios son fundición, laminación del latón, corte de las láminas en formas circulares, perforado, grabado mediante punzón o buril y soldadura.

Son pocos los análisis metálicos que se han realizado en astrolabios con el fin de conocer a fondo el material usado en la elaboración de cada una de sus partes y poder deducir las técnicas metalúrgicas ${ }^{30} \mathrm{y}$ de grabación y perforación usadas en los talleres astrolabistas. Un estudio exhaustivo sobre el proceso completo de construcción de un astrolabio, desde su diseño teórico hasta su ejecución, está aún por hacer.

De entre el medio centenar de astrolabios hispanos, andalusíes y latinos, solo dos han sido sometidos hasta el momento a un análisis metálico: el astrolabio nazarí de Muhammad ibn Zāwal (886H/1481-1482 d.C. $)^{31}$, conservado en el Museo Arqueológico de Granada y el astrolabio latino Destombes realizado en la Marca Hispánica a finales del s. X, conservado en el Instituto del Mundo Árabe de París.

El astrolabio granadino fue sometido a un análisis metálico en el año 1990 por Paul Craddock y Duncan Hook del Research Laboratory del British Museum. Se analizaron la madre, la araña y la alidada $^{32}$.

\begin{tabular}{|c|c|c|c|c|c|}
\hline \multicolumn{7}{|c|}{ PorcentaJe EN PESo (\%) } \\
\hline & Cu & Zn & Sn & Ag & Pb \\
\hline Madre & 73 & 8.5 & 4.5 & 0.1 & 10 \\
\hline Araña & 74 & 24 & 0.2 & 0 & 1.5 \\
\hline Alidada & 78 & 19 & 0.5 & 0 & 2 \\
\hline
\end{tabular}

Tabla 1. Composición de las distintas partes del astrolabio nazarí de ibn Zāwal.

30 B.D. NEWBURY et al.,"The Astrolabe Craftsmen of Lahore and Early Brass Metallurgy", Annals of Science, 63-2 (2006), pp. 201-213. Este excelente estudio realizado en 2006 por el laboratorio de arqueometalurgia de la Universidad de Lehigh en colaboración con el Adler Planetarium de Chicago sobre un conjunto de ocho astrolabios realizados en Lahore en el s. XVII es un buen ejemplo de los tipos de análisis metálicos que se deberían hacer con todos los astrolabios para poder elaborar una tesis consistente sobre su proceso de fabricación y la configuración de los talleres astrolabistas.

31 Detalles de este astrolabio en: A. MENDOZA EGUARAS, "El astrolabio del Museo Arqueológico de Granada", Boletín de la Real Academia de Bellas Artes de Granada, 1 (1990), pp. 139-167; El legado cientifico andalusí, op. cit., 1992, p. 227.

32 No se incluyeron láminas en el análisis porque lamentablemente no nos ha llegado ninguna de ellas. El astrolabio tiene grabadas las curvas almicantarates y acimutales correspondientes a la latitud de Granada $\left(37^{\circ}\right)$ en el fondo de la madre (A. MENDOZA EGUARAS, op. cit., p. 158). La tabla solo muestra los metales con presencia relevante, cobre $(\mathrm{Cu})$, zinc $(\mathrm{Zn})$, estaño $(\mathrm{Sn})$, plomo $(\mathrm{Pb})$ y plata $(\mathrm{Ag})$. Otros metales como el hierro y el níquel están presentes en porcentajes menores del 1\% y se deben considerar como impurezas asociadas al proceso metalúrgico de elaboración de la aleación. 
La primera conclusión que ofrece el estudio es que, si bien todas las piezas son de latón, no tienen los mismos porcentajes de metales en su composición. La madre contiene más estaño y sobre todo más plomo, un 10\%. El plomo proporciona a la aleación más resistencia al desgaste pero le resta ductilidad, es decir capacidad de ser laminada. Pero la madre es la pieza con más grosor y sin perforaciones por lo que puede perder un poco de esa ductilidad a cambio de resistir mejor el desgaste. Parece, por tanto, que la elección del tipo de latón elegido para hacer cada pieza no fue aleatoria.

El otro astrolabio que ha sido sometido a análisis metálicos ha sido el Destombes conservado en el Instituto del Mundo Árabe de París. Las razones para el estudio fueron las sospechas sobre su autenticidad ${ }^{33}$ que se extendieron por la comunidad científica al aparecer en manos del coleccionista francés Marcel Destombes en $1962^{34}$. Su morfología y sus inscripciones en latín situaban su construcción en la Europa cristiana de finales del s. X y eso lo convertía, si no era falso, en el más antiguo astrolabio latino llegado a nuestros días. La puesta en común de los resultados confirmaron la autenticidad de la pieza, su datación a finales del $\mathrm{s}$. $\mathrm{X}^{35} \mathrm{y}$ su construcción posiblemente en Barcelona, dato este derivado del estudio paleográfico de las inscripciones que presentan variantes catalanas del latín propias de la segunda mitad del s. $\mathrm{X}^{36}$.

Centrándonos ya en los análisis metálicos realizados al astrolabio Destombes, se realizaron en 1987 unas primeras pruebas mediante la técnica de fluorescencia de rayos X por el Research Laboratory for Archeology and the History of Art de Oxford. Los márgenes de error de esas medidas y la continuación de los debates sobre la autenticidad del astrolabio llevaron al CNRS (Centre National de la Recherche Scientifique) a someter a las distintas partes del astrolabio a una nueva batería de pruebas a partir de 1990, esta vez usando técnicas nucleares ${ }^{37}$ cuyos márgenes de error son despreciables.

33 J. DE GRAEVE, "La provenance de l'astrolabe Carolingien de Marcel Destombes, Physis, 32 (1995), pp. 209-216; G. BEAUJOUAN, “L'authenticité de l'astrolabe dit Caroligien”, Physis, 32 (1995), pp. 439-450.

34 M. DESTOMBES, op. cit. (1962).

35 Ibid., p. 1. Destombes data el astrolabio en torno al 986, fecha en que el Condado de Barcelona se separa de la Lotaria francesa; J. SAMSÓ MOYA, op. cit., 1995, p. 250. La franja cronológica que plantea Julio Samsó estaría entre mediados del s. X y la caída del califato de Córdoba en 1031. Sostiene que el astrolabio Destombes debió tener como modelo un astrolabio califal realizado en Córdoba.

36 A.M. MUNDÓ, op. cit., pp. 303-321. Este paleógrafo presenta inscripciones catalanas de la segunda mitad del s. X con el mismo tipo de letra que la que tiene el astrolabio y llega a plantear que el lugar exacto de construcción del astrolabio debió ser Barcelona puesto que la lámina dedicada a su uso en esa ciudad muestra el valor de su latitud, 4130', subrayado y eso pudo ser una señal dejada por su constructor.; J. SAMSÓ MOYA, op. cit. (1995), y "La introducción de la astronomía árabe en Cataluña a fines del siglo X", Ante el milenario del reinado de Sancho el Mayor. Un rey navarro para España y Europa. XXX Semana de Estudios Medievales. Estella, Pamplona, 2004, p. 304. Julio Samsó presenta más evidencias sobre el uso en textos andalusíes del término "Ifranŷa" (Francia) para identificar tanto a la Marca Hispánica como a la Francia transpirenaica por lo que la inscripción "Roma et Francia" de la lámina de latitud 41³0' debe leerse "Roma y Barcelona", ciudades con esa latitud. No hay ninguna ciudad francesa al otro lado de los Pirineos con latitud $41^{\circ} 30^{\prime}$.

37 B. GRATUZE y J.N. BARRANDON, "Nouvelles analyses de l'astrolabe latin AI 86-31", Physis, 32 (1995), pp. 433-438. En concreto se sometió a todas las piezas a: 1) Técnica PIXE (medida de la emisión de rayos $\mathrm{X}$ inducida por protones); 2) Técnica PAA (análisis por activación protónica); 3) Técnica FNAA (análisis mediante activación de neutrones rápidos). 
Estas tres técnicas nucleares confirmaron los datos de 1987 respecto a la composición de las aleaciones y sobre todo descartaron definitivamente que fuera una falsificación.

\begin{tabular}{|c|c|c|c|c|}
\hline \multicolumn{5}{|c|}{ Porcentaje EN PESo (\%) } \\
\hline & Cu & Zn & Sn & Pb \\
\hline Madre & 79 & 17 & 2.5 & 0.1 \\
\hline Lámina & 79 & 17 & 2.5 & 0.1 \\
\hline Araña & 81 & 16 & 2.6 & 0.2 \\
\hline Alidada & 66 & 32 & 0 & 1.3 \\
\hline
\end{tabular}

Tabla 2. Composición de las distintas partes del astrolabio latino Destombes.

Los resultados muestran que la araña no es de la misma pieza que la madre y la lámina pero es de una aleación muy similar. La alidada es completamente distinta y su composición con ausencia total de estaño y el alto porcentaje de zinc y sobre todo con más plomo, que la hace más resistente al desgaste, podría ser de época posterior.

\section{Los Tratados del Astrolabio}

Es preciso destacar, aunque sea brevemente, el papel esencial que jugaron los textos conocidos como Tratados del Astrolabio para difundir tanto la construcción como el uso de los astrolabios. Ya se ha indicado que el más antiguo que nos ha llegado lo escribió en griego Juan Philopon de Alejandría en el año 642 d.C. A partir de esta fecha, son los astrónomos y astrolabistas islámicos los que elaboran y difunden estos libros. Todos tienen la misma estructura: una primera parte con el proceso detallado de construcción del astrolabio y una segunda parte con las instrucciones para su uso correcto. Los Tratados del Astrolabio que se escribieron en al-Andalus tuvieron gran difusión e influencia tanto en el resto del Islam, sobre todo en Egipto, como en la Europa cristiana y son un perfecto ejemplo de la bidireccionalidad de la transmisión de las ideas científicas entre oriente y occidente en la Edad Media. El primero fue el tratado de Maslama al-Maŷrìtī (m. 397 H / 1007 d.C.), luego los de sus discípulos Ahmad ibn al-Saffār (m. 1035 d.C.) y Abū-l-Qāsim ibn al-Samh (m. 1035 d.C.) y los tratados de astrolabios universales, el gran invento de la astrolábica andalusí, escritos por Abū Ishāq Ibrahīm ibn Yahyāa al-Naqqāsh al-Qurtubī al-Zarqālluh (10291100 d.C.), conocido como Azarquiel, por Alī ibn Jalaf al-Saŷŷar en 1071 d.C. y por Ahmad ibn Husayn ibn Bāso (m. 709 H/1309 d.C.) ${ }^{38}$ a principios del s. XIV.

38 Hay muchos estudios realizados sobre estos tratados. Ver R. MARTÍ y M. VILADRIDCH, "En torno a los tratados de uso del astrolabio hasta el s. XIII en al-Andalus, la Marca Hispánica y Castilla", Nuevos 


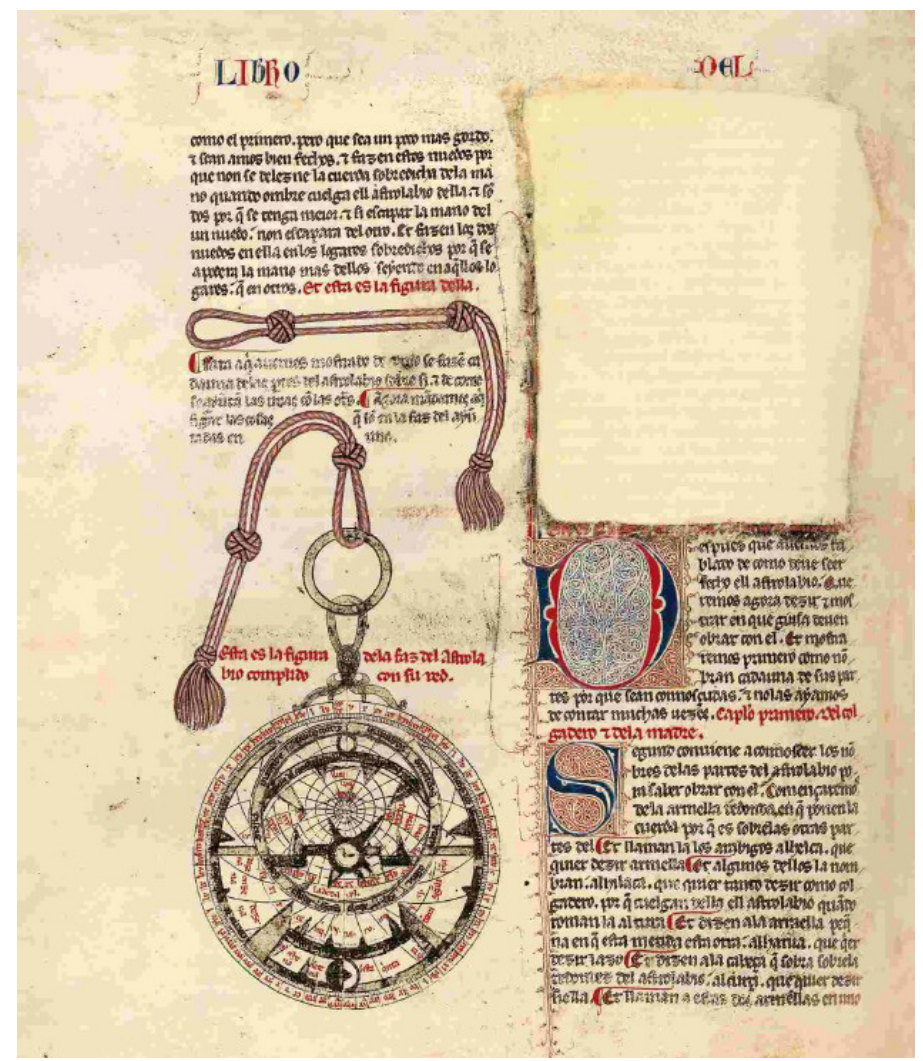

Fig. 5. Libro del Astrolabio Llano de Alfonso X el Sabio. Biblioteca Histórica "Marqués de Valdecilla" de la Universidad Complutense de Madrid, Ms. 156, f. 75v.

La primera traducción, de la que tenemos constancia, de un texto árabe al latín se hizo precisamente de un Tratado del Astrolabio, entre el 978 y el 995, por Lupitus Barchenonensis, arcediano de la catedral de Barcelona ${ }^{39}$. Hay que llegar al s. XIII y al scriptorium de Alfonso X de Castilla para encontrar el primer tratado del astrola-

Estudios sobre Astronomía española en el siglo de Alfonso X, Barcelona, 1983, pp. 9-74; J. SAMSÓ MOYA, "À propos de quelques manuscrits astronomiques des biblioteques de Tunis: contribution a une étude de l'astrolabe dans l'Espagne musulmane", Actas del II Coloquio Hispano-Tunecino de Estudios Históricos, Madrid, 1973, pp. 171-190; R. PUIG, "Instrumentos universales en al-Andalus", El legado científico andalusí, op. cit., 1992, pp. 67-73; E. CALVO LABARTA, "La ciencia en la Granada nazarí", El legado cientifico andalusí, op. cit., 1992, pp. 120-121; J.M. MILLAS VALLICROSA, Estudios sobre Azarquiel, Madrid, 1943; y D.A. KING, "Universal solutions in Islamic astronomy", Acta Historica Scientarum Naturalium et Medicinalium, 39 (1987), pp. 121-132.

39 J. SAMSÓ MOYA, op. cit., 2004, pp. 305-314. Precisamente ese primer Tratado del Astrolabio traducido del árabe al latín, cuenta con una excelente reproducción del que es el astrolabio andalusí más antiguo que no nos ha llegado materialmente pero que conocemos gracias a ese dibujo. El astrolabista que lo construyó fue Jalaf ibn al-Mucād, tal como se lee en el dorso. Las ilustraciones reproducen la araña, el dorso, la madre y las seis láminas grabadas por ambas caras. 
bio escrito en castellano, el Libro del Astrolabio Llano (1276-1278), que forma parte del compendio astronómico alfonsí que él tituló Libro del Saber de Astrología. Ese tratado del astrolabio, atribuido al erudito judío Rabbí Ishāq ben Sīd (Rabiçag de Toledo ${ }^{40}$, contiene un excelente corpus de dibujos para facilitar la comprensión del texto ${ }^{41}$ (Fig. 5). El astrolabio cuya construcción y uso se detalla en el tratado, corresponde a la tipología de los astrolabios andalusíes de su época.

\section{Conclusiones}

Aunque el astrolabio nació en la Grecia helenística, fue a partir del s. X y de la mano del Islam cuando empezó a incorporar elementos decorativos, al configurarse como un instrumento al servicio del culto islámico para el establecimiento de las horas de rezo y de la qibla. La comparación de las arañas de astrolabios andalusíes de los distintos periodos cronológicos pone de manifiesto lo que tienen de común, por ser elemento esencial para cumplir sus funciones de instrumento científico, y lo que ofrecen de singular y artístico.

La difusión del astrolabio a los reinos cristianos hispanos se inició a finales del s. X a través de la Marca Hispánica y de allí irradió a toda Europa. Los astrolabios construidos en territorio cristiano tienen sus inscripciones en latín, carecen de las líneas de las horas de rezo islámico e incorporaron también su propio repertorio de elementos decorativos. Sus calidades técnicas, en cuanto a instrumento de precisión, son más desiguales que las de sus homólogos andalusíes. La presencia de inscripciones hebreas e islámicas en los astrolabios latinos hispanos es una prueba más de la multiculturalidad en la España medieval.

Los Tratados del Astrolabio detallaban los métodos geométricos que el astrolabista debía seguir y las tablas astronómicas que debía consultar durante el proceso constructivo, pero dejaban libertad para la incorporación de elementos decorativos que singularizaran cada instrumento y lo imbricaran con la producción artística de su época, sin comprometer su funcionamiento.

40 L. FERNÁNDEZ FERNÁNDEZ, Arte y ciencia en el scriptorium de Alfonso X el Sabio, Puerto de Santa María, 2013, pp. 63-65; J. SAMSÓ MOYA, "La ciencia española en la época de Alfonso el Sabio", Alfonso X. Toledo 1984, Toledo, 1984, p. 97. El Libro del Astrolabio Llano es obra original del escritorio alfonsí pues no se indica que sea traducción de ningún texto en árabe si bien se han encontrado ya las fuentes árabes utilizadas para su elaboración que procedían de la escuela del astrónomo andalusí Maslama al-Maŷrītī (m. $397 \mathrm{H} / 1007$ d.C).

41 El Libro del Saber de Astrologia de Alfonso X consta de 16 tratados dedicados a distintos temas, de los que cuatro se refieren a astrolabios: Libro del astrolabio redondo (sobre la construcción y uso de un astrolabio esférico), el Libro del astrolabio llano (el que nos concierne por referirse a la construcción y uso de un astrolabio planisférico), el Libro de la Lámina Universal (sobre el astrolabio universal de Alī ibn Jalaf al-Saŷŷar ) y el Libro de la Azafea (sobre el astrolabio universal de Azarquiel). Ver L. FERNÁNDEZ FERNÁNDEZ, op. cit., 2013, pp. 220-230; J. SAMSÓ MOYA, op. cit., 1984, pp. 89-101; M. VILADRICH, "Una nueva evidencia de materiales árabes en la astronomía alfonsí", De Astronomia Alphonsi Regis. Actas del Simposio sobre Astronomía Alfonsí, Barcelona, 1987, pp. 105-116; J.D. NORTH, "The Alfonsine books and some astrological techniques", De Astronomia Alphonsi Regis, op. cit., 1987, pp. 43-50; y M. RICO Y SINOBAS, Libros del Saber de Astronomía del rey Alfonso X de Castilla, Madrid, 1863 (edición reimpresa en 2002 por el Institute for the History of Arabic-Islamic Science, Frankfurt), t. II, pp. 225-294. 
El casi medio centenar de astrolabios que nos han llegado, construidos en la Península Ibérica entre los siglos X y XV, componen el mejor conjunto de instrumentación científica medieval europea $\mathrm{y}$, al mismo tiempo, son una muestra de la producción suntuaria del momento. Si bien se han realizado estudios metálicos en los latones de dos astrolabios hispanos, no es suficiente su número para extraer conclusiones sobre el proceso completo de construcción de los astrolabios. La investigación debe proseguir. 